\title{
Continuity of Care: Supporting New Graduates to Grow Into Confident Practitioners
}

\author{
Vanessa Clements, Deborah Davis, and Jennifer Fenwick
}

\begin{abstract}
AIM: This article describes how newly qualified midwives experienced their rotation into birth suite and a continuity of midwifery care model. The findings are part of a larger study that aimed to describe graduate midwives' expectations and experiences of their transition to practice.
\end{abstract}

BACKGROUND: Knowledge and understanding of how midwives make the transition from student to registered midwife remain limited. However, the literature suggests that this time is a critical period for a new graduate. Although transition support programs for midwives exist in New South Wales, Australia, there appears to be an ad hoc approach to their design, implementation, and effectiveness.

METHOD: A descriptive qualitative approach to elicit the experiences of 38 newly qualified Australian midwives. Telephone interviews and focus groups were used to collect the data. Content analysis was used to analyze the data set.

FINDINGS: The birthing environment was identified as the clinical area, which elicited the greatest level of apprehension for the midwives, whereas those with the opportunity to rotate into a midwifery continuity of care model rated the experience positively.

CONCLUSION: The findings of the study suggest that the newly graduated midwives felt a sense of social and professional belonging to the midwifery continuity of care models in which they worked.

KEYWORDS: newly graduated midwife; transition support programs; birth suite; models of care; continuity of care; hierarchy

\section{INTRODUCTION}

The ability of new midwives to successfully make the transition from student to registered practitioner has implications for both the profession of midwifery and the maternity health service as a whole. With the shortage of midwives nationally and internationally (Altier \& Krsek, 2006; Heath, Duncan, Lowe, Macri, \& Ramsay, 2002; Sullivan, Lock, \& Homer, 2011), it is essential that existing and newly qualified staff be retained within the profession. This is highly relevant in the Australian context where losses of newly graduated midwives are reported to be high (Heath et al., 2002). In studies of both midwives and nurses, an effective transition support program ${ }^{1}$ was seen to have a positive effect on the retention of staff (Beecroft, Kunzman, \& Krozek,
2001; Boon, Graham, Wainwright, \& Warriner, 2005; Levett-Jones \& Fitzgerald, 2005).

The quality of support provided to new graduates has several ramifications for the profession beyond retention in the workforce. The most pertinent perhaps is the ability of future midwives to be able to practice within their full scope of practice and continue to drive the change agenda currently being shaped and promoted by the peak midwifery body, the Australian College of Midwives (ACM; Brodie \& Barclay, 2001; Heath et al., 2002). This is particularly the case in New South Wales (NSW), where maternity health care policy has recognized the need to refocus care on the needs of women using primary health principles and to better use the skills and expertise of the midwife (NSW Health, 2003, 2010). As a result, new models of woman-centered care have 
emerged such as midwifery-led stand-alone birth centers (Ryde and Belmont hospitals), caseload group practices (the Royal Women's Hospital, Sydney), and the introduction of publicly funded home birth services (St. George Hospital, Sydney). These new models of care by their very nature enable midwives to practice within the full scope of their role (Australian Nursing \& Midwifery Council, 2006; Brodie \& Barclay, 2001). Carolan and Hodnett (2007) comment, however, that although these changes are certainly in the interest of pregnant women, a challenge exists for midwives who have been working for extended time in a fragmented system of maternity care.

Although student midwives must gain experience in continuity of care (Australian Nursing \& Midwifery Council, 2009), most of our transition support programs only provide newly graduated midwives with experience in fragmented models of maternity care with rotations through antenatal, labor and birth, and postnatal services. This does little to assist newly graduated midwives to consolidate their knowledge and skills or build their confidence in midwifery-led continuity of care models of service delivery. Although the success and sustainability of these models of care depend on several factors, the role of the newly graduated midwife in embracing these models and working within them should not be underestimated. Effective transition programs form a key part of the strategy to ensure this success can be facilitated.

Standards and guiding principles for formalized transition support and/or programs for both newly graduated midwives and nurses exist and the importance of this support is not in question (Heath et al., 2002). What is unclear, however, is how this "support" should be structured and delivered to meet both the individual needs of graduates and the employing health service. It is widely acknowledged in the literature that this is an area in need of further research (Charnley, 1999; LevettJones \& Fitzgerald, 2005; Parker, Plank, \& Hegney, 2003). In reviewing what was available to newly graduated nurses, Levett-Jones and Fitzgerald (2005) aimed to challenge the status quo. They argued that there was little available evidence to inform the content and structure of formal graduate transition support programs and questioned whether alternative approaches should be explored (Levett-Jones \& Fitzgerald, 2005). One alternative they suggested was to focus on developing clinical environments, which would enable a culture of supportive practice. They argued that this approach would have the additional benefit of encouraging continuing professional development for the rest of the team (LevettJones \& Fitzgerald, 2005). Although their paper is solely focused on nursing, the questions raised have relevance to midwifery because the profession questions how best to support newly graduated midwives who are educated through a range of undergraduate and postgraduate programs.

There is much written on how the new graduate experiences a sense of unpreparedness at the point of registration (Charnley, 1999; Clark \& Holmes, 2007; Fleming, Poat, Curzio, Douglas, \& Cheyne, 2001; Gerrish, 2000; Jasper, 1996; Newton \& McKenna, 2007). Although their education has given them the knowledge to underpin their chosen profession, the reality of putting this knowledge into practice is often challenging and stressful (Charnley, 1999; Jasper, 1996; Newton \& McKenna, 2007). New graduates can find the increased level of responsibility and accountability for managing clinical care particularly overwhelming (Fleming et al., 2001; Jasper, 1996; Maben \& Clark, 1998; van der Putten, 2008). The reality of this increased responsibility when moving from student to qualified professional can be confronting for many and the literature identifies that new graduates can experience a form of "reality or transition shock" (Charnley, 1999; Delaney, 2003; Duchscher, 2009; K. Evans, 2001; van der Putten, 2008). This phenomenon is described as occurring when, having studied extensively to qualify in their chosen profession in the expectation that this will prepare them for the challenges of their new role, the new graduate finds themselves feeling totally unprepared and left "reeling" from the reality of practice (Charnley, 1999; K. Evans, 2001; Gerrish, 2000; van der Putten, 2008). As a result, the new graduate may experience feelings of fear, apprehension, uncertainty, and deficiency, as well as insecurity (Charnley, 1999; Duchscher, 2009; Gerrish, 2000).

Transition support programs aim to reduce the feeling of shock that new graduates experience by providing support because they acclimatize to the work setting and grow in confidence. Most transition support programs attempt to achieve this by providing the graduate with the opportunity to consolidate their skills in various clinical areas including antenatal clinics, birth suite, and postnatal wards. Few programs include experience in continuity of midwifery care models though, as we will highlight in this article, this experience can have a significantly beneficial effect on the newly graduated midwife.

\section{AIM}

The findings presented in this article are part of a larger study that explored the expectations and experiences of 
newly qualified midwives during their transition from student to registered midwife (Clements, Fenwick, \& Davis, 2012). The objective of this article is to describe newly graduated midwives' experiences of birth suite and rotations into continuity of care models.

\section{METHOD}

This study employed a qualitative design. Burns and Grove (2003, p. 493) describe qualitative research as the "systematic, subjective approach used to describe life experiences and give them meaning." In essence, qualitative research is an umbrella term under which several methodologies and methods sit. These differing approaches may be quite separate or in fact overlap; however, the common theme is that they all adopt an interpretive and naturalistic approach (Holloway, 1997; Whitehead, 2013). In this study, a descriptive explorative approach was used. Rich description that "accurately portrays the characteristics of people, situations, or groups and/or the frequency with which certain phenomena occur" is the aim (Polit \& Beck, 2006, p. 498). In line with the early work of Sandelowski (2000), Burns and Grove (2005) argue that this approach is justified when there is limited information on the phenomena under study. Descriptive studies of this nature provide evidence on which further research can build.

Multisite ethics approval was granted from the relevant university and hospital ethics committees.

\section{Setting and Participants}

Thirty-eight newly graduated midwives were recruited from 14 public maternity hospitals in Sydney, Australia. The midwives had been prepared for practice through a range of educational backgrounds (i.e., Bachelor of Midwifery $[\mathrm{BM}]$, graduate diploma $[\mathrm{GD}]$, and masters $[\mathrm{M}]$ programs). Thirty-six midwives were undertaking their graduate year within a structured transition support program. The remaining two midwives, although not in a formal program, were afforded the opportunity to rotate through clinical areas and attend several study days.

There was only one hospital that provided all their graduate midwives with an opportunity to rotate into a midwifery continuity of care/carer model. In this facility, the model was referred to as Midwifery Group Practice (MGP). Two further facilities offered limited opportunities to rotate into similar models. The continuity of care models consisted of groups of midwives (4-10) who provided continuity of antenatal, intrapartum, and postnatal care (up to 2 weeks) to a defined caseload of women. Women accessing these models had most of their antenatal care within hospital clinics, gave birth in either birth centers or birthing suites, and were encouraged to discharge home within 4-6 hours of birth. Midwives remained the woman's carer regardless of any change in risk status. Sixteen of the midwives participating in this study had the opportunity to rotate into a continuity of care model.

\section{Recruitment}

Potential participants received a study package, which included a letter of invitation, a participant information sheet, and a consent form. If willing to participate, the newly graduated midwives were asked to return the consent form in the attached reply paid envelop. Once received, the newly graduated midwife was contacted by the research team and a convenient time made to conduct a telephone interview and/or participate in a focus group at the end of the transition period (12 months). Thirty-two newly graduated midwives took part in telephone interviews and seven attended a focus group (for more detail, please see Clements et al., 2012).

\section{Data Collection}

The telephone interviews were conducted by a team of experienced midwives from areas outside those the participant was working in. The team met prior to commencement of the study and developed a pro forma to ensure consistency across the team. E-mail, teleconferences, and field notes were also used to promote uniformity. The pro forma consisted of several openended questions based on the objectives of the study. The interviews commenced with participants being asked to reflect on their experiences over the past 12 months and the support they had received. Each interview lasted approximately $30-45 \mathrm{~min}$ and was recorded using hand-taken notes and bullet points. Pertinent quotations from midwives were also recorded. Although taping and transcribing interviews can be advantageous, this is not always necessary (Russell \& Gregory, 2003).

As themes emerged from the analysis process, an additional group of newly graduated midwives were recruited and consented to attend one of two focus groups $(n=7)$. Sessions were recorded on an iPod and subsequently transcribed verbatim. 


\section{Data Analysis}

Latent content analysis was used to analyze the data set (Berg, 2001). This analysis technique aims to explore and interpret the underlying meaning of data (Berg, 2001; Graneheim \& Lundman, 2004). All the written data were transcribed into a word document. Transcripts were then read several times to facilitate researcher immersion in the data set. Initial thoughts and perceptions were recorded and discussed between researchers. The process of line-by-line coding commenced with the grouping of words or statements referred to as "meaning units" (Graneheim \& Lundman, 2004). Using the process of constant comparison meaning, units were subsequently clustered together forming subthemes. Subthemes were grouped to generate larger themes. Finally, relationships between themes facilitated a "mental picture" or understanding of the midwives experiences (Harding \& Whitehead, 2013, p. 142).

The focus group data were transcribed. Because the purpose of the focus groups was to validate the emerging themes, the meaning units already identified formed a template or analysis framework.

\section{Location and Subjectivity of the Researchers}

The study presented in this article was undertaken by midwifery clinicians and researchers and forms part of the first author's high degree by research dissertation (Clements, 2012). The first author graduated from a U.K. undergraduate or direct entry midwifery program in the early 1990s. On qualifying, she found herself working in a birth suite largely unsupported and, as she described, "extremely anxious." The huge disparity between being a third-year student and a first-year midwife was one that she was completely unprepared for. Much has changed in the intervening years in the United Kingdom. Access to transition programs has become the norm for newly graduated midwives because their value and benefit have been identified (Boon et al., 2005; Burke, 1994; Maggs, 1994; The North West London Hospitals NHS Trust, 2008; Powell, 2005). Upon arriving and practicing in Australia, however, the first author observed newly graduated midwives undergoing similar experiences to her own. This experience was disconcerting and it became increasingly obvious that many students either did not take up a midwifery position on graduation, or left soon afterward.

As a clinical midwifery consultant, the first author began to hypothesize about the level of support provided to new graduates and how these experiences impacted on each graduate's decision making process. The desire to investigate this issue within her own health service area prompted her to seek out academic and research support from several like-minded midwifery leaders. All had similar philosophies, which included seeing the midwife as the person best placed to provide primary care to a healthy pregnant woman and her family. In addition, all demonstrated a commitment to mainstream maternity service reform, which included advocating for continuity of midwifery carer models. It is therefore important to acknowledge that it is through this "lens" (Morse, 1994) that data were collected and analyzed. The analysis and interpretation of the data reflect to some extent the hermeneutical notion that research is part of and participates in generating the experience: the data (Malpras, 1992; Munhall, 1994). As Harding and Whitehead (2013) suggest, our findings thus became a subjective construction in which our own knowledge, beliefs, and attitudes played a role (Harding \& Whitehead, 2013).

\section{FINDINGS}

In this article, we present the findings related to the newly graduated midwives' experiences of their clinical rotation to birth suite. This is contrasted to the experience of rotating into a continuity of midwifery care model. For identification, the newly graduated midwives will be referred to in this article as the "midwives." Other midwives-that is, those not in their first year of practice-will be referred to as "experienced midwives" or by their job title, for example, "midwifery manager" or "educator."

\section{The Birth Suite: A Stressful Experience}

Feelings of "stress," "discomfort," and "anxiety" were reported most frequently in relation to the birth suite rotation. The midwives reported that their new-found level of responsibility in this distinct area of practice was particularly overwhelming and difficult to cope with. One of the graduate diploma-prepared midwives summed it up by describing birth suite as the "scariest and most daunting experience because of the intensity of the work and just how much you need to know" (Carla).

The stress experienced by the midwives, particularly around birth suite, was seemingly linked to what participants described as "their new reality" (Mandy): being 
responsible for making decisions regarding a woman's labor and birth care. The midwives considered this to be a new experience because "as a student, you never have to make a decision on your own" (Bina). It was one that they did not necessarily feel prepared for. Feelings of apprehension about decision making were compounded by the "fear" of making a mistake. Feeling "scared" about making an error was common among all the participants. Not unlike her colleagues, Mandy expressed her worries in the following way: "If there is nobody there to ask what do you do? ... You've got very little expertise or experience in this area and you know if something goes wrong you're responsible." Her anxiety was real and she went on to talk about her fear of losing her registration over "a mistake." Sadly, by the end of the year, these pressures and fears had led to Mandy's decision to leave midwifery and return to her previous area of work. This was not an uncommon experience. For example, Nancy had made a decision to leave the public hospital system. She stated that the "level of responsibility is too high. [I] can't come to work with this level of stress and anxiety." This participant opted to go to a private hospital where she considered she would have less responsibility and thus be able to reduce her stress. Another midwife reported not being able to complete her birth suite rotation because of the stress and having to access the staff counselor to help her cope with coming to work.

Compounding these feelings were birth suite environments that were described by some as hierarchical in nature where rules, status, and power were valued. The midwives perceived that many of the "rules" and "structures" they came across were instigated by experienced midwives to control and manipulate the environment on behalf of themselves and the women. In these environments, midwives perceived there to be a "pecking order" that placed them near the bottom, assigning them little or no status or power. Their perception that this was indeed a reality was reinforced in several ways. For example, many commented on how they were the ones required to fill staff shortages and/or move to other areas when busy because the more experienced midwives either did not want to or could not because of their lack of skills in other areas: "We get moved because of staff shortages ... other midwives are not skilled in birthing ... or they [the experienced midwives] refuse to go" (Kim). As a result, the midwives felt that their "learning needs" were ranked below those of the other experienced midwives and/or the organization.

In addition, some midwives reported how the birth suite environment was dominated by fear and intimidation. Midwives considered that they were continually under surveillance from experienced midwives. Feeling "watched" and under "constant monitoring" represented an additional level of pressure for the midwives, accompanied by the threat of disapproval should they "step out of line." One Bachelor of Midwifery midwife described her experience in the following way:

They [the experienced midwives] are just looking at me waiting, waiting for me to make a mistake, waiting for me to step one foot out of line and they are just going to hammer me something shocking. You know and how do you work like that? - Suzie

Although there were negative reports of the working environment, there were also comments by midwives verifying that although the birth environment was busy, they were still offered a level of support that assisted them meet their learning needs. For example, one midwife commented that she "never felt that there was ever a time when I couldn't get help; even when the ward was at its busiest, they were always happy to help me" (Mina).

In stark contrast to the experiences of the midwives in the birth suite environment were those provided by midwives who were afforded the opportunity to work within a midwifery continuity of care model. The support obtained within the continuity of care model was highly valued and had a positive impact on midwives' confidence.

\section{Midwifery Continuity of Care Models: An Added Bonus for Some}

The midwives who were given the option to work in a midwifery continuity of care model during their transition year rated the experience highly. The opportunity appeared to provide the midwives with a level of support not always experienced in their other clinical rotations. Working closely with midwives who were able to selfregulate their working life, shared a similar philosophy of care, and were considered to be woman centered fostered a supportive learning atmosphere for the new midwife to work within: "Being part of a group that was much less hierarchal than the hospital ... It was all about the women ... They [MGP midwives] were open to teaching me ... there was much more time to be reflective on what you were learning" (Bina).

Having the opportunity to witness and be part of care focused on building relationships and supporting 
normal birth was highly valued; as one midwife expressed "an injection of normality." This sentiment was repeated by others because it appeared to provide a sense of what "being a midwife" was all about. As one midwife described, "the relationships built between the midwives and the women are so much better . . . the woman is supported much better ... [the women] seem happier regardless of outcomes ... normal birth is encouraged ... [I] have seen lots of water births ... it's what midwifery is" (Kim).

The midwives reported feeling extremely supported within the midwifery continuity of care models. This level of support increased their learning, clinical confidence, and competence. For example, Mina expressed, "[I] loved it because in the continuity of care model as a midwife, it enabled you to really work within scope of practice ... made you think about safe practice ... quite challenging but [I] learnt so much."

There was also evidence that the confidence and competence gained during what was on average a fairly short rotation (on average 4 weeks), assisted them to better adapt to other areas, most specifically the birth suite. For example, Tracey reported that "it's great to have that one-to-one support from the midwives ... the four weeks in Midwifery Group Practice were fantastic and helped with my anxiety on the delivery suite."

None of the midwives who experienced a continuity of midwifery care model described being anxious, stressed, and/or fearful during this rotation. These opportunities were, however, extremely limited with only one site offering all midwives a rotation into a midwifery continuity of care model. Thus, across all hospitals, there were midwives who expressed their dissatisfaction at the limited opportunities to work within these models. Elle, for example, said, "I want to go to the group practice but have only been able to get experience in the hospital... now I will have to unlearn things as it is a different focus." Others like Zara explained feeling professionally disadvantaged as a result of not being afforded this opportunity: "without this experience [I] think it will be difficult for me to get employment in a midwifery model." As a result, some midwives made the decision to leave their current employment and/or transition support program to access these models elsewhere.

\section{DISCUSSION}

Exploring graduates' experiences of the clinical rotations associated with their transition support programs revealed two contrasting experiences: that of the birth suite and continuity of care models. Clinical rotations to the birth suite were described as stressful by participants in this study so much that several participants had to seek counseling or chose to resign from their midwifery positions. This finding supports the international evidence and confirms that rotating to birth suite is both challenging and anxiety provoking (Hughes \& Fraser, 2011; Nursing and Midwifery Council, 2010). Consistent with the existing midwifery and nursing literature was the finding that graduates' new-found sense of responsibility and need to make decisions around a woman's care potentially heightened their anxiety (Fleming et al., 2001; Newton \& McKenna, 2007; Nursing and Midwifery Council, 2010). Compounding this was the "fear" of missing something and/or making a mistake in what they perceive as a clinically critical area (Clark \& Holmes, 2007; Gerrish, 2000; Higgins, Spencer, \& Kane, 2010; Jasper, 1996; Maben \& Clark, 1998; van der Putten, 2008). In addition, comments about losing their registration as a result of making a clinical error resonate with those made by participants in Higgins et al. (2010) study who similarly expressed worrying about litigation and the loss of registration.

In sharp contrast were the positive experiences of new midwives who had the opportunity to work within a continuity of care/carer model where they were partnered with midwives carrying a defined caseload (Homer, Brodie, \& Leap, 2008). Rotation into a model where midwives provided care to individual women across pregnancy, birth, and early parenting was seen as an opportunity to witness how midwives established and maintained positive relationships with women while working autonomously and to the full scope of their practice (Sullivan et al., 2011). The increased confidence this type of experience seemed to afford the new midwife is likely to be a result of being exposed to midwives who were role modeling autonomous decision-making behavior. Researchers, such as Baird (2007), argue strongly that if we expect students and new graduates to develop these skills, they must be given opportunities to observe these in practice. Baird (2007) goes on to caution that the current dominant medical culture within the birthing environment impacts on decision making even during normal labor and birth, resulting in fewer opportunities for students and midwives to hone their skills and confidence in this area.

It is likely that the egalitarian nature of these types of models also played a part in generating positive reflections about the experience. Continuity of care models are underpinned by the principles of woman-centered care and partnership with woman and 
between midwives (Guilliand \& Pairman, 2010; Hunter, 2006; Sullivan et al., 2011). These models often have a fairly "flat" management structure because everyone is expected to self-manage their time and workload. The newly qualified midwives commented that this less hierarchical structure fostered a supportive learning environment where the focus of attention was not only on the woman and her care but also on supporting the new midwife. This engendered a sense of "belonging," which appeared to have been absent within the traditional hospital birth suite environment.

Hunter (2004) provides some insight about why this may have been important for the newly graduated midwives. In her U.K. ethnographic study, Hunter (2004) explored how midwives managed and experienced emotion at work. She found that the hospital and community environments provided very different work settings and associated ideological values. For example, hospital-based midwives aligned themselves with the institution while those working in community were "with woman" (Hunter, 2004, p. 267). She suggests that there should be an acceptance that midwives can thrive in these different environments. Hunter argues that conflict and stress occurs when organizations fail to develop appropriate strategies to support midwives, particularly the newly qualified midwife. She goes on to comment on the importance of preserving the ideals while recognizing the realities of today's clinical environment (Hunter, 2004).

The contrasting findings between the midwives' positive experiences in continuity of care and the hospital birth suite environment are notable and need further exploration. The findings of this study suggest that many midwives experienced the traditional birth suite environment as hierarchical. Midwives perceived themselves to be low in the pecking order. This finding is similar to the documented experiences of midwifery and nursing students at the end of their preregistration education (Begley, 2001; Bluff \& Holloway, 2008). Although it is accepted that the participants in this study were no longer students, it is of note that most had previously been in the midwifery student role within the hospitals where they undertook their transition support program. As such, their place in the hierarchy could be perceived as preexisting. Johnstone, Kanitsaki, and Currie's (2007) study of 11 new graduate nurses and 34 key stakeholders (including nurse unit managers, clinical teachers, and senior nurse administrators) highlighted this issue, demonstrating how staff continued to regard and behave as if the new graduates were students. As a result, the newly graduated midwives often found it difficult to ascertain their position in the hierarchy of the birth suite environment. This situation exacerbated feelings of being unsupported and isolated. This study demonstrates that the culture of the birth environment can have a significant impact on midwifery practice and, in particular, the development of autonomous midwifery practice.

The need to feel accepted by and included in the team has been identified as an important aspect of transition into practice for both midwives (Blaka, 2006; Steele, 2009) and nurses (Duchscher, 2009; J. Evans, Boxer, \& Sanber, 2008). A sense of belonging to the team promotes confidence, enhances clinical experiences, and increases knowledge retention (Blaka, 2006; Duchscher, 2009; J. Evans et al., 2008; Steele, 2009). Malouf and West's (2011) in-depth study of nine newly graduated nurses in Sydney suggests that the importance of being accepted as a member of the team cannot be underestimated in relation to the professional development of a new graduate. These authors discussed how the forming of social relationships was central to the new graduates' development and related to their sense of belonging and ability to perform their nursing duties. Blaka (2006) not only acknowledges the need for social inclusion into the team but also makes the distinction of the need for professional acceptance. The latter needs to be developed over time because the new graduate demonstrates clinical knowledge and skill (Blaka, 2006). It would seem from the findings presented that clinical experiences or rotations into continuity of care models, early in their transition period, enable the new midwife to attain some level of social and professional acceptance.

The Australian and international literature suggests that transition support programs or some form of structured support for all newly graduated midwives is essential. Transition support programs have been demonstrated in the nursing and midwifery literature to be cost-effective, improve recruitment and retention, and promote confidence and competence in the new graduate (Beecroft et al., 2001; Pine \& Tart, 2007). However, we also need to consider how we can best support midwives to feel confident in working to their full scope of practice and providing maternity care in ways that are likely to dominate future maternity services, that is, continuity of care models (Homer et al., 2008). This study suggests that experience as a graduate in continuity of care models confers several benefits. The experience allowed the graduate to develop their confidence in labor and birth care within the context of a partnership with the childbearing woman. Midwives were able to take this new-found confidence and woman-centered 
approach into future clinical rotations. Not unlike the experiences of women in continuity of care models, one could hypothesize that this way of working ameliorated the impact of institutionalization on the new graduate (Fenwick et al., 2012; Kirkham, 2010). Ideally, it appears that this rotation should take place during the early months of their transition period.

Certainly, more research is required to identify the specific needs of newly graduated midwives. However, our work has highlighted how working within continuity of care models positively supports new midwives during their transition to practice. The key principles underpinning such models could be used as a "blueprint" for designing transition support programs that best support midwives to develop into strong competent clinicians confident in working to the International Confederation of Midwives' definition of the midwife.

\section{LIMITATIONS}

This study has limitations that require consideration when interpreting its findings. The relatively small sample size, which equates to a $36 \%$ response rate, was disappointing. Additional focus groups were designed to check and validate the emerging themes. However, caution must be taken in making any generalizations based on the findings of this research. Similarly, the metropolitan and public health service focus of the study makes any generalization of the findings across all health care settings difficult. The use of interview pro formas was included to ensure inter-interview consistency. However, although the pro formas were completed for each telephone interview, recordings and direct transcripts were not made. It is acknowledged that because they were not directly transcribed, meaning may have been lost because of interviewer interpretation; however, this decision was made in view of resource and time constraints.

\section{CONCLUSION}

The findings of the study suggest that the newly graduated midwives felt a sense of social and professional belonging to the midwifery continuity of care models in which they worked. Certainly, these experiences were reported more favorably with no references to stress or anxiety, in contrast to the experiences reported within the traditional birth suite environment. Although further research is warranted, the evidence from this study indicates that newly graduated midwives should be able to access a clinical rotation within midwifery continuity of care models at the start of their transition support program. This would enable them to consolidate and gain experience in all aspects of midwifery care simultaneously.

\section{NOTE}

1. A structured program designed to support newly registered midwives and nurses while they transition from student to registered practitioner. Programs can vary in length from 3 months to 1 year but most include various learning strategies such as educational sessions, clinical rotations, and the provision of a mentor or opportunities for debriefing.

\section{REFERENCES}

Altier, M. E., \& Krsek, C. A. (2006). Effects of a 1-year residence program on job satisfaction and retention of new graduate nurses. Journal for Nurses in Staff Development, 22(2), 70-77.

Australian Nursing \& Midwifery Council. (2006). National competency standards for the midwife. Dickson, ACT: Author.

Australian Nursing \& Midwifery Council. (2009). Standards and criteria for the accreditation of nursing and midwifery courses leading to registration, enrolment, endorsement and authorisation in Australia-with evidence guide. Dickson, ACT: Author.

Baird, K. (2007). Exploring autonomy in education: Preparing student midwives. British Journal of Midwifery, 15(7), 400-405.

Beecroft, P. C., Kunzman, L., \& Krozek, C. (2001). RN internship: Outcomes of a one-year pilot program. Journal of Nursing Administration, 31(12), 575-582.

Begley, C. M. (2001). 'Knowing your place': Student midwives' views of relationships in midwifery in Ireland. Midwifery, 17, 222-233.

Berg, B. L. (2001). Qualitative research methods for the social sciences (4th ed.). Needham Heights, MA: Allyn \& Bacon.

Blaka, G. (2006). Newcomers' learning of midwifery practice in a labour ward: A socio-cultural perspective. Learning in Health and Social Care, 5(1), 35-44.

Bluff, R., \& Holloway, I. (2008). The efficacy of midwifery role models. Midwifery, 24(3), 301-309. http://dx.doi .org/10.1016/j.midw.2005.02.008 
Boon, J., Graham, B., Wainwright, M., \& Warriner, S. (2005). Is preceptorship valuable? Midwives, 8(2), 64-66.

Brodie, P., \& Barclay, L. (2001). Contemporary issues in Australian midwifery regulation. Australian Health Review, 24(4), 103-118.

Burke, L. M. (1994). Preceptorship and post-registration nurse education. Nurse Education Today, 14(1), 60-66.

Burns, N., \& Grove, S. K. (2003). Understanding nursing research (3rd ed.). Philadelphia, PA: Saunders.

Burns, N., \& Grove, S. K. (2005). The practice of nursing research. Conduct, critique and utilization (5th ed.). St. Louis, MO: Elsevier.

Carolan, M., \& Hodnett, E. (2007). 'With women' philosophy: Examining the evidence, answering the questions. Nursing Inquiry, 14(2), 140-152.

Charnley, E. (1999). Occupational stress in the newly qualified staff nurse. Nursing Standard, 13(29), 33-36.

Clark, T., \& Holmes, S. (2007). Fit for practice? An exploration of the development of newly qualified nurses using focus groups. International Journal of Nursing Studies, 44, 1210-1220.

Clements, V. (2012). New graduate midwives' experiences of their transition support programs. Sydney, Australia: University of Technology Sydney.

Clements, V., Fenwick, J., \& Davis, D. (2012). Core elements of transition support programs: The experiences of newly qualified Australian midwives. Sexual \& Reproductive Healthcare, 3(4), 155-162. http://dx.doi.org/http:// dx.doi.org/10.1016/j.srhc.2012.08.001

Delaney, C. (2003). Walking a fine line: Graduate nursed' transition experiences during orientation. Journal of Nursing Education, 42(10), 437-443.

Duchscher, J. E. B. (2009). Transition shock: The initial stage of role adaptation for newly graduated Registered Nurses. Journal of Advanced Nursing, 65(5), 1103-1113.

Evans, J., Boxer, E., \& Sanber, S. (2008). The strengths and weaknesses of transitional support programs for newly registered nurses. Australian Journal of Advanced Nursing, 25(4), 16-22.

Evans, K. (2001). Expectations of newly qualified nurses. Nursing Standard, 15(41), 33-38.

Fenwick, J., Hammond, A., Raymond, J., Smith, R., Foureur, M., Homer, C. S. E., \& Symon, A. (2012). Surviving not thriving: Newly qualified midwives' transition to practice. Journal of Clinical Nursing, 21(13-14), 2054-2063.

Fleming, V., Poat, A., Curzio, J., Douglas, V., \& Cheyne, H. (2001). Competencies of midwives with single or dual qualifications at the point of registration in Scotland. Midwifery, 17, 295-301.
Gerrish, K. (2000). Still fumbling along? A comparative study of the newly qualified nurse's perception of the transition from student to qualified nurse. Journal of Advanced Nursing, 32(2), 473-480.

Graneheim, U. H., \& Lundman, B. (2004). Qualitative content analysis in nursing research: Concepts, procedures and measures to achieve trustworthiness. Nurse Education Today, 24(2), 105-112.

Guilliand, K., \& Pairman, S. (2010). The midwifery partnership: A model for practice (2nd ed.). Christchurch, New Zealand: New Zealand College of Midwives.

Harding, T., \& Whitehead, D. (2013). Analysing data in qualitative research. In Z. Schneider \& D. Whitehead (Eds.), Nursing and Midwifery Research. Methods and apprasial for evidence-based practice (4th ed., pp. 141-160). Sydney, Australia: Elsevier.

Heath, P., Duncan, P., Lowe, E., Macri, S., \& Ramsay, J. (2002). National review of nursing education 2002. Our duty of care. Canberra, Australia: Australian Department of Education, Science and Training.

Higgins, G., Spencer, R. L., \& Kane, R. (2010). A systematic review of the experiences and perceptions of the newly qualified nurse in the United Kingdom. Nurse Education Today, 30(6), 499-508. http://dx.doi.org/10.1016/j .nedt.2009.10.017

Holloway, I. (1997). Basic concepts for qualitative research. Oxford, United Kingdom: Blackwell Science Ltd.

Homer, C. S. E., Brodie, P., \& Leap, N. (2008). Midwifery continuity of care. A practical guide. Sydney, Australia: Churchill Livingstone.

Hughes, A. J., \& Fraser, D. M. (2011). 'SINK or SWIM': The experiences of newly qualified midwives in England. Midwifery, 27(3), 382-386. http:dx.doi.org/10.1016/j .midw.2011.03.012

Hunter, B. (2004). Conflicting ideologies as a source of emotion work in midwifery. Midwifery, 20(3), 261-272. http://dx.doi.org/10.1016/j.midw.2003.12.004

Hunter, B. (2006). The importance of reciprocity in relationships between community-based midwives and mothers. Midwifery, 22(4), 308-322. http://dx.doi .org/10.1016/j.midw.2005.11.002

Jasper, M. (1996). The first year as a staff nurse: The experiences of a first cohort of Project 2000 nurses in a demonstration district. Journal of Advanced Nursing, 24(4), 779-790.

Johnstone, M. J., Kanitsaki, O., \& Currie, T. (2007). The nature and implications of support in graduate nurse transition programs: An Australian study. Journal of Professional Nursing, 24(1), 46-53. http://dx.doi.org/10.1016/j .profnurs.2007.06.003

Kirkham, M. (2010). The midwife-mother relationship (2nd ed.). London, United Kingdom: Macmillan. 
Levett-Jones, T., \& Fitzgerald, M. (2005). A review of graduate nurse transition programs in Australia. Australian Journal of Advanced Nursing, 23(2), 40-45.

Maben, J., \& Clark, J. M. (1998). Project 2000 diplomates' perceptions of their experiences of transition from student to staff nurse. Journal of Clinical Nursing, 7(2), 145-153.

Maggs, C. (1994). Direct but different: Midwifery education since 1989. British Journal of Midwifery, 2(12), 612-616.

Malouf, N., \& West, S. (2011). Fitting in: A pervasive new graduate nurse need. Nurse Education Today, 31(5), 488-493. http://dx.doi.org/10.1016/j.nedt.2010.10.002

Malpras, J. E. (1992). Analysis and hermeneutics. Philosophy and Rehetoric, 25(2), 93-123.

Morse, J. M. (1994). Emerging from the data: The cognitive processes of analysis in qualitative inquiry. In J. M. Morse (Ed.), Critical issues in qualitative research methods (pp. 24-43). London, United Kingdom: Sage.

Munhall, P. L. (1994). Revisioning phenomenology. Nursing and health science research. New York, NY: National League of Nursing Press.

Newton, J. M., \& McKenna, L. (2007). The transitional journey through the graduate year: A focus group study. International Journal of Nursing Studies, 44, 1231-1237.

The North West London Hospitals NHS Trust. (2008). Preceptorship midwives. Midwives, 11(4), 52.

NSW Health. (2003). Models of maternity service provision across NSW. Sydney, Australia: Author.

NSW Health. (2010). Towards normal birth in NSW (PD2010_045). Sydney, Australia: Author.

Nursing and Midwifery Council. (2010). The MINT Project: Evaluation of whether Midwifer Teachers bring a unique contribution particuarly in the context of outcomes for women and their families. London, United Kingdom: University of Nottingham.

Parker, V., Plank, A., \& Hegney, D. (2003). Adequacy of support for new graduates during their transition into the workplace: A Queensland, Australia study. International Journal of Nursing Practice, 9, 300-305.

Pine, R., \& Tart, K. (2007). Return on investment: Benefits and challenges of a baccalaureate nursing residency program. Nursing Economic\$, 25(1), 13-18, 39.
Polit, D. F., \& Beck, C. T. (2006). Essentials of nursing research methods, appraisal, and utilization (6th ed.). Philadelphia, PA: Lippincott Williams \& Wilkins.

Powell, A. (2005). Starting as we mean to go on: Supporting newly qualified practitioners. British Journal of Midwifery, 13(11), 726.

Russell, C. K., \& Gregory, D. M. (2003). Evaluation of qualitative research studies. EBN users' guide. Evidence Based Nursing, 6(2), 36-40.

Sandelowski, M. (2000). Focus on research methods. Whatever happened to qualitative description. Research in Nursing and Health, 23, 334-340.

Steele, R. (2009). Gaining competence and confidence as a midwife. British Journal of Midwifery, 17(7), 441-447.

Sullivan, K., Lock, L., \& Homer, C. S. E. (2011). Factors that contribute to midwives staying in midwifery: A study in one area health service in New South Wales, Australia. Midwifery, 27(3), 331-335. http://dx.doi.org/10.1016/j .midw.2011.01.007

Van der Putten, D. (2008). The lived experience of newly qualified midwives: A qualitative study. British Journal of Midwifery, 16(6), 48-58.

Whitehead, D. (2013). Common qualitative methods. In Z. Schneider \& D. Whitehead (Eds.), Nursing and midwifery research. Methods and appraisals for evidence-based practice (4th ed., pp. 103-122). Sydney, Australia: Elsevier.

Correspondence regarding this article should be directed to Vanessa Clements, New South Wales Pregnancy and Newborn Services Network, 170 Hawkesbury Road Westmead, NSW 2145, Australia. E-mail: clementsvanessa@hotmail.com

Vanessa Clements, Master of Midwifery, Research Candidate Centre for Midwifery and Family and Child Health, University of Technology, Sydney. Clinical Midwifery Consultant, Maternity Support Network (MSN), NSW Pregnancy and Newborn Services Network (PSN).

Deborah Davis, PhD, Clinical Chair and Professor of Midwifery, ACT Health Directorate and University of Canberra Faculty of Health.

Jennifer Fenwick, PhD, Professor of Midwifery, School of Nursing and Midwifery, Maternity and Family Unit, Research Centre for Clinical and Community Practice Innovation (RCCCPI), Griffith Health Institute, GriffithUniversity. Adjunct Professor, University of Technology, Sydney. 